University of Montana

ScholarWorks at University of Montana

$1-17-2003$

\title{
Wing-Assisted Incline Running and the Evolution of Flight
}

Kenneth P. Dial

University of Montana - Missoula, kdial@mso.umt.edu

Follow this and additional works at: https://scholarworks.umt.edu/biosci_pubs

Part of the Biology Commons

Let us know how access to this document benefits you.

\section{Recommended Citation}

Dial, Kenneth P., "Wing-Assisted Incline Running and the Evolution of Flight" (2003). Biological Sciences Faculty Publications. 33.

https://scholarworks.umt.edu/biosci_pubs/33

This Article is brought to you for free and open access by the Biological Sciences at ScholarWorks at University of Montana. It has been accepted for inclusion in Biological Sciences Faculty Publications by an authorized administrator of ScholarWorks at University of Montana. For more information, please contact scholarworks@mso.umt.edu. 
affect the interpretation of muscle function from EMGs. Muscle activation may result in isometric or isotonic (even lengthening isotonic) contractions that are impossible to distinguish. However, our interpretations of the contributions of abdominal muscles to trunk bending and of the pectineus muscle to pelvic limb movement are conservative because we account for every muscle that attaches to the epipubic bones. The movements of the epipubic bones can only be produced by the muscles tested. In addition, the muscle activation resulted in musculoskeletal movement, which confirms that tension was generated during the stance phase. Thus, it is irrefutable that the abdominal muscles elevate, and the pectineus depresses these bones.

7. T. D. White, J. Mamm. 71, 79 (1990).

8. Three female Monodelphis (weighing 94 to $104 \mathrm{~g}$ ) and three Didelphis (weighing 0.5 to 2.6 kilos; one was female) were used in the study. Motor patterns were recorded using standard fine-wire electromyography and synchronized high-speed video (at 200 $\mathrm{fps}$ ) while the animals moved at speeds of 0.15 to $0.50 \mathrm{~m} \mathrm{~s}^{-1}$ on a motorized treadmill (19). Limb and epipubic bone movements were videotaped (at 60 fps) using a Picker Corporation Model K2601 videofluoroscope as the animals ran on the same treadmill and speed range. Thin metal rods were implanted along each epipubic bone to visualize epipubic bone movements relative to the pelvis and hindlimb. Animal care and research protocols were in accordance with approved Ohio University Institutional Animal Care and Use Committee guidelines.

9. D. R. Carrier, J. Exp. Biol. 152, 453 (1990).

10. W. O. Bennet, R. S. Simons, E. L. Brainerd, J. Exp. Biol. 204, 1979 (2001).

11. D. Ritter, J. Exp. Biol. 199, 2499 (1996).
12. D. R. Carrier, J. Exp. Bio. 180, 75 (1993).

13. M. M. Fife, L. Bailey, D. V. Lee, D. R. Carrier, J. Exp. Biol. 204, 2371 (2001).

14. F. A. Jenkins Jr., Evolution 24, 230 (1970).

15. S. Fourie, Nature 198, 201 (1963).

16. R. Owen, Proc. Zool. Soc. London 1843, 148 (1843)

17. P. P. Gambaryan, How Mammals Run: Anatomical Adaptations (Wiley, New York, 1974).

18. M. Hildebrand, J. Mamm. 58, 131 (1977).

19. S. M. Reilly, Brain Behav. Evol. 52, 126 (1998).

20. We thank A. Biknevicius and the Ohio University College of Medicine for use of the videofluoroscope. $\mathrm{H}$. Streby assisted in the EMG experiments and in video analysis. This work was funded by NSF, an Ohio University Research Challenge grant, and sabbatical support from Buffalo State College.

10 June 2002; accepted 4 December 2002

\title{
Wing-Assisted Incline Running and the Evolution of Flight
}

\author{
Kenneth P. Dial
}

Flapping wings of galliform birds are routinely used to produce aerodynamic forces oriented toward the substrate to enhance hindlimb traction. Here, I document this behavior in natural and laboratory settings. Adult birds fully capable of aerial flight preferentially employ wing-assisted incline running (WAIR), rather than flying, to reach elevated refuges (such as cliffs, trees, and boulders). From the day of hatching and before attaining sustained aerial flight, developing ground birds use WAIR to enhance their locomotor performance through improved foot traction, ultimately permitting vertical running. WAIR provides insight from behaviors observable in living birds into the possible role of incipient wings in feathered theropod dinosaurs and offers a previously unstudied explanation for the evolution of avian flight.

Most species of living birds are altricial, producing naked, thermally dependent, and nonmobile hatchlings that are sequestered in above-ground nests and require substantial parental investment before independence (1). In contrast, offspring of precocial species (e.g., Galliformes and Tinamiformes) hatch fully feathered and are capable of leaving their simple ground nests almost immediately to forage and escape predation. From hatching, chukar partridges (Alectoris chukar) use their well-developed legs to ascend textured surfaces with inclines of up to $45^{\circ}$. However, chicks can also walk and run up steeper slopes while vigorously beating their developing wings (Fig. 1A). With this strategy, called wing-assisted incline running (WAIR), hatchlings negotiate $50^{\circ}$ inclines, 4-day-olds climb $60^{\circ}$ slopes, and 20-day-olds accomplish vertical ascents. Mature birds also combine wing and leg movements to scale overhanging slopes of up to $105^{\circ}$, as well as to traverse lower inclines when exhausted from aerial flights. When employing WAIR, birds reach heights of $>5 \mathrm{~m}$ on vertical surfaces and do not require a running start. Although this behavior is common in nature, WAIR has

Flight Laboratory, Avian Studies Program, Division of Biological Sciences, University of Montana (UM), Missoula, MT 59812, USA. E-mail: kdial@selway.umt.edu

Fig. 1. (A) Incline-running performance on a textured substrate (36grit sandpaper) for chukar partridges with fully feathered (control group) wings during development from posthatchling to 50 days. Shaded area represents angles of shallow incline where birds did not recruit their flapping wings. To ascend steep inclines, developing chicks and adults employ WAIR (nonshaded area). (B) Incline-running performance on textured and nontextured (smooth) substrate for chukar partridges possessing fully feathered (con-

A

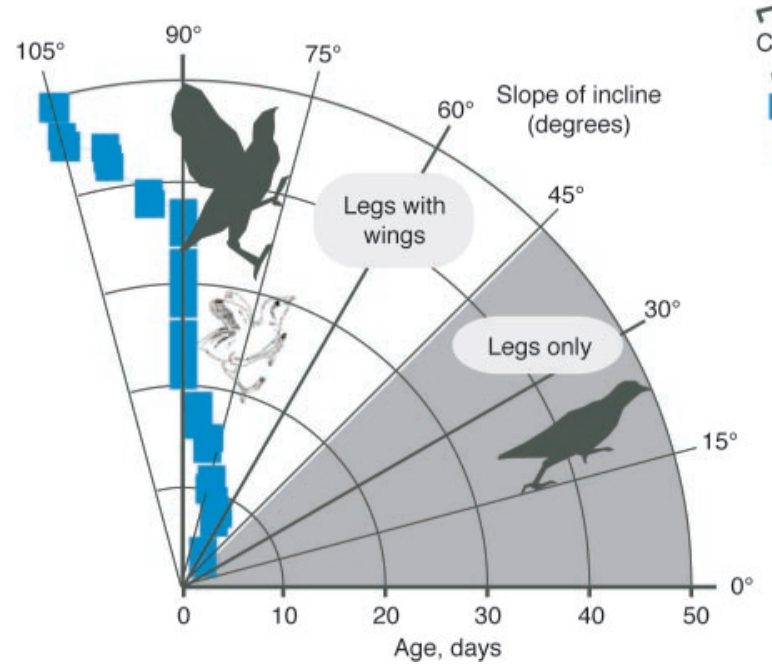

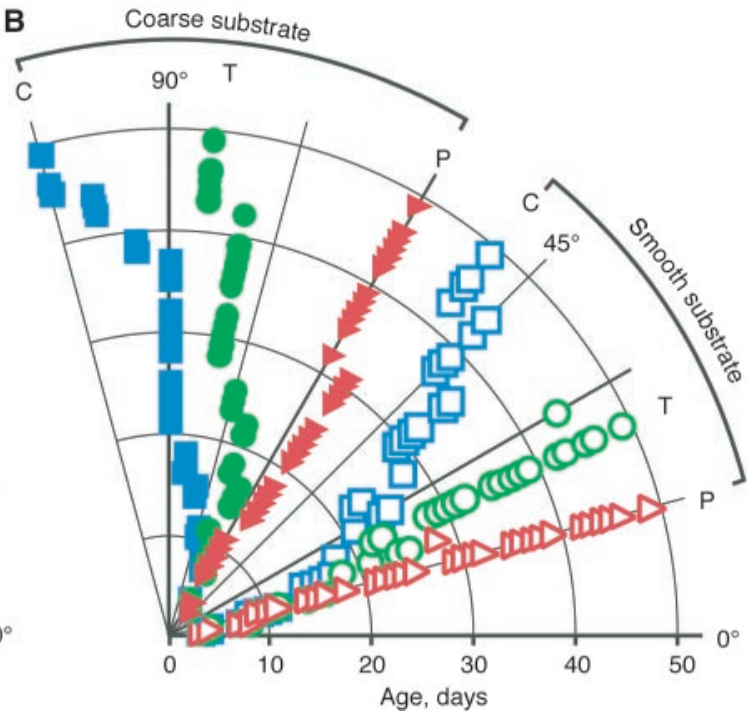

trol, $C$ ), trimmed $(T)$, and plucked $(P)$ wings starting the day after hatching. Data points represent the climbing angle (in $5^{\circ}$ increments) that all five individuals within each of the three groups were able to perform that day. Control animals (feathered wings) were capable of vertical running within 20 days of hatching, whereas plucked birds did not improve incline running performance beyond what they could attain during their first few days posthatching. Birds with trimmed wings and incapable of aerial flight attained intermediate locomotor performance. These data show that hindlimb traction is associated with WAIR performance. 
remained unappreciated because it normally occurs during brief, explosive bouts (e.g., predator escape or retreat to an elevated roost) and requires high-speed recordings (film or video) to visualize the kinematics (movie S1).

To investigate the contribution of the wings to inclined running through ontogeny, I compared the performance of unmodified control partridges to that of birds whose flight feathers (remiges) were trimmed to half the normal surface area and that of birds whose remiges were completely removed (Fig. 1B) (2). Measured performance was similar among groups during the initial posthatching period, when the surface areas of control and modified wings were comparable. After the seventh day posthatching, however, reduction of the remiges significantly decreased the maximum slope that modified birds could ascend. Birds with remiges removed never exceeded a $60^{\circ}$ incline even on textured substrates. Those with half-trimmed remiges were intermediate, lagging control birds by $10^{\circ}$ to $20^{\circ}$ but showing steady improvement through time. These results are consistent with the wings actively assisting the legs in ascending inclined surfaces, effectively acting like the spoilers on a race car to improve traction.
Wing flapping during incline running might produce aerodynamic or inertial forces that lift the bird's center of mass vertically. Alternatively, aerodynamic or inertial forces oriented toward the inclined substrate could increase traction, allowing the legs to propel the body upward. To assess the importance of traction, I tested control and modified birds on slopes covered with textured and smooth surfaces. All three experimental groups were capable of steep ascents on the coarsest substrate and were restricted to slopes below $50^{\circ}$ on the smooth substrate (Fig. 1B). On the nontextured substrate, the birds made little to no forward progress due to slippage, even though these animals possessed and used fully functional wings. Thus, traction, the interaction of the feet with the substrate, is an important component of flap-running locomotion.

Wing kinematics and accelerometers were used to assess the direction of wing forces produced by adult birds as they ascended inclines varying in pitch from $45^{\circ}$ to $90^{\circ}$ (movie S1). Video recordings provided a kinematic record of wing movements (Fig. 2) $(2-4)$. Birds are known to vary the direction of wing movement, or wing-stroke plane angle, to modulate the total wing force vector appropriately for different modes and speeds

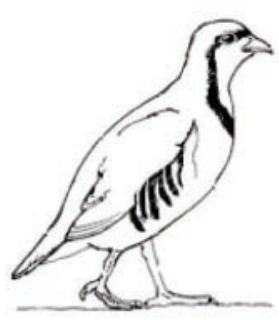

A Horizontal (Walk and run only, no flapping)

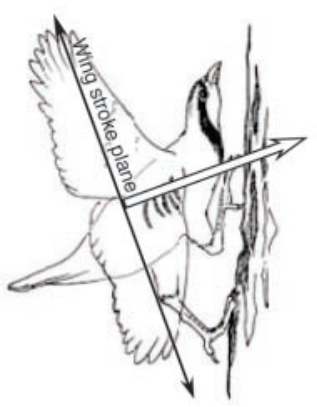

D Vertical

(Run - flapping)
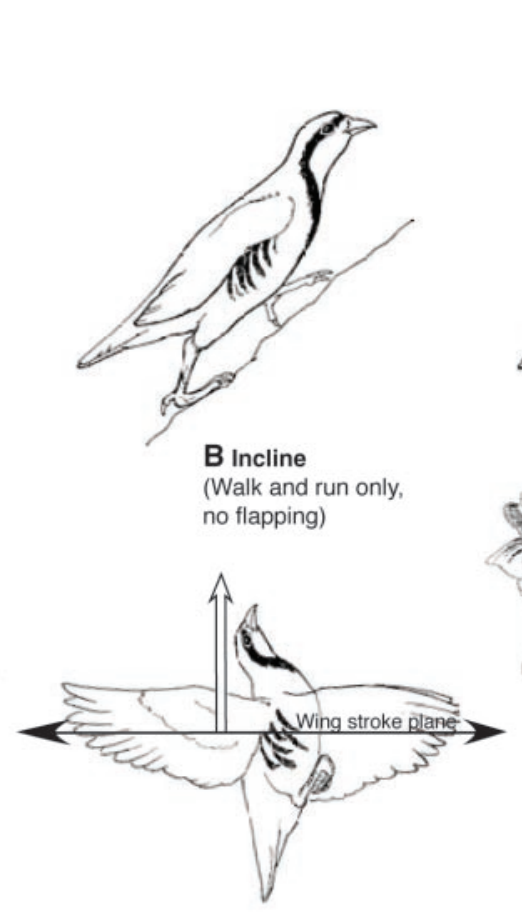

E Vertical flight

(Flapping only)

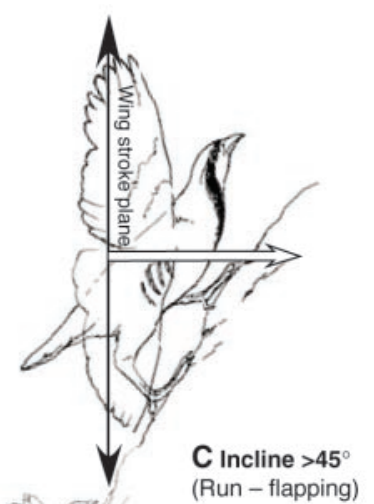

(Run - flapping)

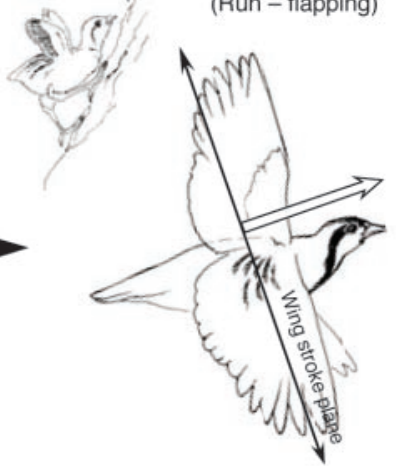

F Horizontal flight (Flapping only)

Fig. 2. Overview of wing excursions during WAIR and proposed transitions accompanying the WAIR origin of flight hypothesis. (A and B) Birds running over level substrates or shallow inclines do not recruit their wings to assist running. However, even partial wing development provides assistance to individuals during incline $\left(>45^{\circ}\right.$ ) locomotor performance (C). (C and D) A portion of the wingbeat cycle (up to $30 \%$ ) involves aerodynamic or inertial forces directed toward the inclined surface, rather than skyward, which is sufficient to augment hindlimb traction during WAIR. (D to F) On mastering vertical inclines, birds attain a transverse (dorsoventral) wing excursion that is required for aerial flight.

of flight. The total aerodynamic force produced by a wing is suggested to be roughly perpendicular to the wing (aerofoil) motion relative to incurrent air. Immature (incapable of flight) and adult birds precisely modify their wing-stroke plane angle to adjust to the slope of an incline. As a bird runs up a steep slope $\left(>45^{\circ}\right)$, the orientation of the wingstroke plane angle imposes a net aerodynamic vector directed toward the incline, which presses the animal against the substrate and creates improved hindlimb traction (Fig. 2, C and D). For each sloped incline, the wingstroke plane angle is reoriented as the bird changes body posture and wing excursion (Fig. 2, C and D). However, kinematic data provide only indirect evidence regarding the orientation of aerodynamic or inertial forces generated by flapping wings.

Therefore, we mounted two accelerometers on each animal's torso (one oriented anteroposteriorly and the other dorsoventrally) to calculate the instantaneous direction and magnitude of whole-body acceleration during $\operatorname{WAIR}(2,5)$. Accelerometer signals were repeatedly coordinated with wing kinematics. These data illustrate that, during a substantial portion of the wingbeat cycle, the bird's center of mass is being directed toward the substrate (Fig. 3). Results from 127 wing beats in three birds demonstrate that whole-body acceleration vectors during the first $50 \%$ of downstroke are oriented upward and forward with a mean magnitude of $3.25 \mathrm{~g}$ (acceleration of gravity) \pm 0.11 (SE) (Fig. 3, A and B). Throughout the last half of downstroke to mid-upstroke, the acceleration vectors are directed toward the inclined substrate with a mean magnitude of $3.04 \mathrm{~g} \pm 0.14$ (Fig. 3, $\mathrm{C}$ to E). During the last $50 \%$ of upstroke, the whole-body accelerations are small (mean $=1.63 \mathrm{~g} \pm 0.10)$ and are generally directed opposite the direction of travel (Fig. 3F). Accelerometer data indicate that a significant portion of the wingbeat cycle involves aerodynamic or inertial forces that push the bird toward the inclined substrate, permitting animals to run vertically.

The origin of avian flight has been the subject of analysis and debate for well over a century (6-12). Major paleontological advances have been made with the recognition that birds derive from theropod dinosaurs and that recently discovered small theropods were feathered $(13,14)$. Our rich knowledge of extant birds - their behavior, life history, and ontogeny-has seemed to offer little insight. Recently, a number of alternative approaches on this subject have been offered, including aerodynamic models (15), character analyses (16), and discussions on the evolution of the flight stroke (17). Nevertheless, a clear delineation of incremental adaptive stages of forelimb evolution necessary to achieve the 


\section{R E P O R T S}

fully developed flapping mechanics as observed among extant species has remained a challenge $(18,19)$.

I propose that the incipiently feathered forelimbs of small, bipedal proto-birds provided the same locomotor advantages for inclined running as are present in extant birds. Whether sprinting across an obstaclefilled terrain or up inclined or even vertical surfaces, being chased, or chasing, an animal capable of employing WAIR enjoys improved hindlimb traction (Fig. 2). In a proto-bird, this behavior would have represented the intermediate stage in the ic wings. The WAIR hypothesis resolves many of the limitations associated with development of flight-capable, aerodynam-

the popular arboreal and cursorial scenerios.

The propulsive excursion of the forelimbs of most tetrapods, in which the forelimbs protract and retract in anteroposterior planes, differs fundamentally from that in flying forms (i.e., birds, bats, and pterosaurs), which primarily involves elevation and depression in a transverse, dorsoventral plane (20). Forelimb excursion during terrestrial flap-running in gallinaceous birds negotiating intermediate slopes $\left(\sim 45^{\circ}\right.$ to $60^{\circ}$ ) has a strong anteroposterior component, in contrast to a transverse stroke during flight (Fig. 2, D and F). As in the intermediate condition exemplified by the glenoid orientation of Archaeopteryx (20), the anteroposterior limb excursion em-
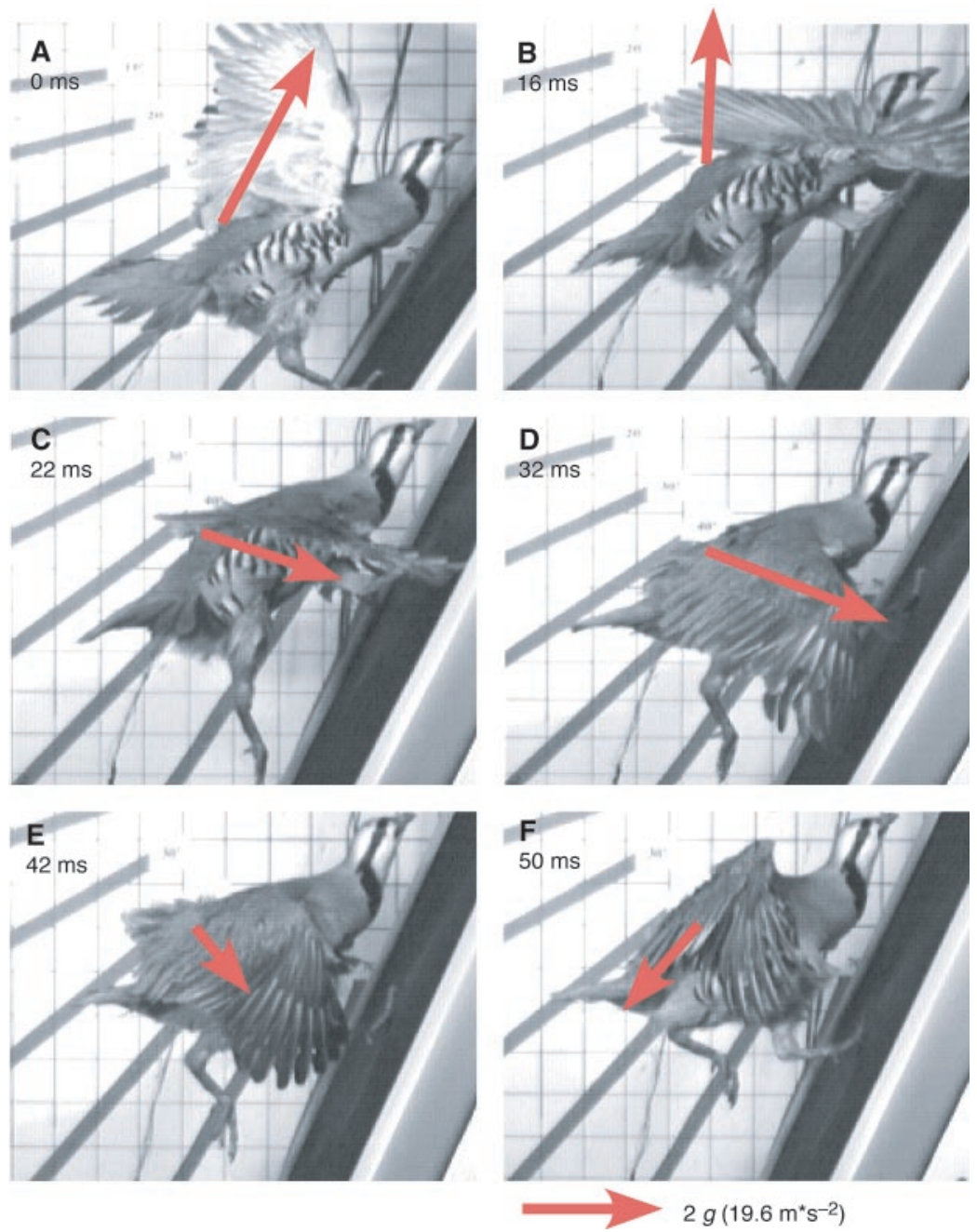

Fig. 3. Instantaneous measure of whole-body acceleration during wing-assisted incline running on a treadmill pitched to $55^{\circ}$. Red arrows depict mean values at six kinematic intervals during the wingbeat cycle: (A) beginning of downstroke, (B) mid-downstroke, (C) late downstroke, (D) end of downstroke, (E) beginning of upstroke, $(\mathbf{F})$ mid-upstroke. Means were determined from 127 wing beats $(n)$ taken from three trials for each of three birds (bird 1, $n=31$; bird 2, $n=56$; bird 3,n= 40). Because acceleration is the only vector component of force, the arrows indicate the direction and relative intensity of the forces acting on the bird's center of mass. During the first half of downstroke $(A)$ and $(B)$, acceleration vectors are directed upward and forward. During the second half of downstroke and through $1 / 3$ of upstroke (B) to (E), the forces experienced by the center of mass are directed toward the substrate and have likely been generated by the wings, thus increasing hindlimb traction. ployed by juvenile and adult ground birds during WAIR exhibits the humeral movement expected of a transitional stage. Although I propose that the net force vectors from proto-wings initially were directed toward the substrate to augment hindlimb traction, redirected movements would have permitted rudimentary aerial ascent and controlled descent from elevated refuges, as is observed in extant juvenile galliforms. The ontogenetic trajectories of WAIR behavior in extant birds offer a plausible scenario for incremental adaptive plateaus that feathered theropods (e.g., Caudipteryx) achieved in developing aerial flight.

\section{References and Notes}

1. J. M. Starck, R. E. Ricklefs, Eds., Avian Growth and Development (Oxford Univ. Press, New York, 1998).

2. Materials and Methods are available as supporting material on Science Online.

3. B. W. Tobalske, K. P. Dial, J. Exp. Biol. 199, 263 (1996).

4. J. V. M. Rayner, Current Ornithology, R. F. Johnston, Ed. (Plenum Press, New York, 1988), vol. 5, pp. 1-66.

5. D. Bilo, A. Lauck, W. Nachtigall, in Biona Report 3, Bird Flight - Vogelflug, W. Nachtigall, Ed. (Gustav Fischer, Stuttgart, Germany, 1985), Pp. 87-108.

6. S. Chatterjee, The Rise of Birds (John Hopkins Press, Baltimore, MD, 1997)

7. C. Darwin, On the Origin of Species (John Murray, London, 1859).

8. A. Feduccia, The Origin and Evolution of Birds (Yale Univ. Press, New Haven, CT, 1996).

9. M. K. Hecht, J. H. Ostrom, G. Viohl, P. Wellnhofer, The Beginnings of Birds (Freunde des Jura-Museums, Eichstatt, Germany, 1985).

10. J. H. Ostrom, Am. Sci. 67, 46 (1979).

11. G. Caple, R. P. Balda, W. R. Willis, Am. Nat. 121, 455 (1983).

12. J. Gauthier, L. F. Gall, Eds., New Perspectives on the Origin and Early Evolution of Birds: Proceedings of the International Symposium in Honor of John H. Ostrom (Yale Univ. Peabody Museum, New Haven, CT, 2002).

13. M. Norell et al., Nature 406, 36 (2002).

14. Q. Ji, P. J. Currie, M. A. Norell, S.-A. Ji, Nature 393,753 (1998).

15. P. Bergers, L. M. Chiappe, Nature 399, 60 (2001).

16. J. P. Garner, G. K. Taylor, A. L. R. Thomas, R. Soc. London B 266, 1259 (1999).

17. K. Padian, L. M. Chiappe, Sci. Am. 278, 38 (1998).

18. W. J. Bock, in (9), pp. 199-208.

19. H. Gee, available at http://www.nature.com/nsu/ 980702/980702-8.html.

20. F. A. Jenkins Jr., Am. J. Sci. 293, 253 (1993)

21. I thank M. W. Bundle, R. J. Randall, and T. R. Dial for their hard work and careful attention to detail while filming, testing, and caring for the birds over the past several years; F. A. Jenkins Jr. and S. M. Gatesy for their input on the manuscript; and A. A. Biewener, D. F. Boggs, D. J. Emlen, E. Greene, R. L. Hutto, D. A. Jenni, J. S. Marks, T. E. Martin, J. J. Sevekya, and B. W. Tobalske for their time and assistance on various aspects of the project. S. Gatesy assisted in the development of Fig. 1, Fig. 2 artwork was prepared by R. Petty, and M. W. Bundle is responsible for recording and analyzing the accelerometer data presented in Fig. 3. Supported by NSF and UM Field Research Station at Fort Missoula.

\section{Supporting Online Material}

www.sciencemag.org/cgi/content/full/299/5605/402/DC1 Materials and Methods

Movie S1

18 September 2002; accepted 4 December 2002 